This is the final peer-reviewed accepted manuscript of:

Lupini C, Felice V, Silveira F, et al. Comparative in vivo pathogenicity study of an ITA genotype isolate (G6) of infectious bursal disease virus. Transbound Emerg Dis. 2019;00:1-7

The final published version is available online at: https://doi.org/10.1111/tbed.13421

Rights / License:

The terms and conditions for the reuse of this version of the manuscript are specified in the publishing policy. For all terms of use and more information see the publisher's website.

This item was downloaded from IRIS Università di Bologna (https://cris.unibo.it/)

When citing, please refer to the published version. 


\section{Comparative in vivo Pathogenicity Study of an ITA Genotype Isolate (G6)}

\section{of Infectious Bursal Disease Virus}

Running title: In vivo pathogenicity study of an IBDV strain of the ITA genotype (G6)

Caterina Lupini $^{1 *}$, Viviana Felice ${ }^{1}$, Flavio Silveira ${ }^{1}$, Giulia Mescolini ${ }^{1}$, Giacomo Berto ${ }^{2}$, Valeria Listorti ${ }^{1}$, Mattia Cecchinato ${ }^{3}$, Elena Catelli ${ }^{1}$

${ }^{1}$ Department of Veterinary Medical Sciences, University of Bologna, Ozzano dell’Emilia (BO), Italy

${ }^{2}$ CEVA Salute Animale, Agrate Brianza (MB), Italy

${ }^{3}$ Department of Animal Medicine, Production and Health, University of Padua, Legnaro (PD), Italy

* corresponding author

\section{Summary}

Recently, a new genotype of infectious bursal disease virus (IBDV), named ITA, was detected in IBDvaccinated Italian broilers. Genome characterisation revealed ITA to be a genetically different IBDV, belonging to genogroup 6 according to a recently proposed IBDV classification. The currently available clinical data do not allow any definition of the degree of pathogenicity of the ITA-IBDV isolates. In the present study, a pathogenicity trial was conducted by the oral inoculation of specific-pathogen-free (SPF) chickens. Birds were housed in poultry isolators and inoculated at 35 days of age with an ITA-IBDV isolate (35 birds) or a strain belonging to the G1a genogroup as a comparison (35 birds). Control birds (25 birds) were contextually mock-inoculated with sterile water. Birds were observed daily for clinical signs and at $0,7,14$, 21 and 28 days post-inoculation (dpi) were bled for IBDV antibody detection. At 2, 4, 7, 14, 21 and 28 dpi, five birds from each of the inoculated groups, and three from the control group, were euthanised and subjected to a post-mortem examination; the bursa:body weight and thymus:body weight ratios were calculated. Microscopic lesions of the bursa and thymus were scored on the basis of lymphoid necrosis and/or depletion or cortex atrophy, respectively. Both viruses induced a subclinical course of disease, as neither clinical signs nor mortality were recorded during the study, even in the presence of typical IBDV gross and microscopic lesions. Bursal damage, measured by the bursa:body weight ratio, was more noticeable and precocious after ITA-IBDV inoculation. Histopathology scores of the bursa, indicative of rapid lymphoid depletion, confirmed the aggressiveness of the ITA-IBDV strain in this organ. This study showed that, although the ITA-IBDV 
strain tested causes infection with a subclinical course, it induces severe damage to lymphoid tissues. Therefore, its circulation in birds might be a threat for the poultry industry and may jeopardise the success of the production cycle.

Keywords: Avibirnavirus, Chicken, Gumboro disease, Infectious bursal disease, Pathogenicity trial

\section{INTRODUCTION}

Infectious bursal disease (IBD) is a highly contagious immunosuppressive disease in chickens caused by a bisegmented dsRNA virus (IBDV) that belongs to the family Birnaviridae and genus Avibirnavirus (Delmas et al., 2019). There are two recognised serotypes of IBDV, designated 1 and 2; only serotype 2 viruses have been known to cause naturally occurring disease in chickens. The primary target organ is the bursa of Fabricius, where the virus infects and destroys dividing IgM-bearing B cells (Hirai \& Calnek, 1979). Serotype 1 IBDV includes strains with different antigenicities and pathogenicities. "Classical" isolates, first reported by Cosgrove (1962), can cause acute clinical disease in susceptible birds, characterised by ruffled feathers, dehydration, watery diarrhea, prostration and mortality. Infection with classical strains can also be characterised by an absence of clinical signs and mortality, in the presence of bursal damage (Abdul, Murgia, Rodriguez-Palacios, Lee, \& Saif, 2013; Sreedevi, LeFever, Sommer-Wagner, \& Jackwood, 2007). In the early 1980s, antigenic "variants" of the virus were identified in the USA (Saif, 1984); vaccine strains available at that time were not able to elicit full protection. "Variant" isolates typically do not cause clinical signs of disease, but always cause discernible immunosuppression (Sharma, Dohms, \& Metz, 1989). "Very virulent" strains of IBDV emerged in the late 1980s and spread through Europe and Asia in the 1990s; these strains were shown to be mostly antigenically similar to the classical isolates (Abdel-Alim \& Saif, 2001) and were able to cause outbreaks of disease characterised by an exacerbated acute phase and more than $70 \%$ mortality in susceptible chickens. Regardless of the pathogenicity of the strain and the severity of clinical signs, IBDV infection is always associated with damage to the bursa of Fabricius and immunosuppression, often followed, in the field, by infections with other pathogens and an impaired immune response to other vaccinations (Sreedevi et al., 2007). The high mutation rate of the IBDV genome could lead to the emergence of strains with new antigenic and pathogenic properties, which could persist and circulate in immunised commercial chickens (Ingrao, Rauw, Lambrecht, \& van den Berg, 2013). In 2011, a new genotype of IBDV, named ITA, 
was detected in Italian broilers vaccinated with live IBDV vaccines (Lupini et al., 2016). Full genome characterisation confirmed ITA to be a genetically different IBDV (Felice et al., 2017) and a recently proposed classification for IBDV into genogroups placed the ITA genotype into genogroup 6, together with a few other strains detected in Saudi Arabia and Russia (Michel \& Jackwood, 2017). The currently available epidemiological and clinical data regarding strains of IBDV of the ITA genotype do not allow for a precise definition of their degree of pathogenicity, since the viruses have been detected in IBDV-vaccinated broilers, sometimes with poor performance. Vaccination applied in the field provided some degree of immune protection, which could have masked the clinical course of the disease. The ITA-IBDV genotype has peculiar molecular characteristics, as it has most of the mutations that affect charged amino acids in key positions of the hypervariable region of the VP2 protein. These mutations may be associated with major changes in virus properties, with VP2 being the primary antigenic and pathogenicity determinant of IBDV (Nagarajan \& Kibenge, 1997).

The aim of this study was to determine the pathogenicity of a strain of IBDV belonging to the ITA genotype. A pathogenicity study was conducted by inoculation of specific-pathogen-free (SPF) chickens in secure isolation conditions with an IBDV strain recognised to belong to the ITA genotype. Clinical signs, macro/microscopic lesions, antibody response and damage to the bursa of Fabricius and thymus were assessed.

\section{MATERIAL AND METHODS}

Ninety-five SPF white leghorn chickens (Istituto Zooprofilattico della Lombardia e dell'Emilia Romagna) were used and housed in secure isolation facilities for the duration of the study. Two field isolates of IBDV were used in this study (named according to the new nomenclature proposed by Jackwood, Schat, Michel and de Wit (2018)): IBDV 1/chicken/Italy/1829/11/(G6) (herein referred to as ITA) and IBDV 1/chicken/Italy/24II/12/(G1a) (herein referred to as G1a). The G1a IBDV (sequence data submitted to the GenBank database under accession number MN102364) was detected in 2012 in an Italian broiler flock not live-vaccinated for IBDV and was used here for comparative purposes. Isolation and titration of the IBDV strains were performed in SPF chicken embryonated eggs via the chorioallantoic membrane (CAM) route, as previously described (Silveira et al., 2019). Viruses were harvested from CAMs, titrated and used in the trial, and examined by molecular assays to exclude contamination of other avian pathogens (Imai, Mase, 
Yamaguchi, Yuasa, \& Nakamura, 1998; Raue \& Hess, 1998; Fouchier et al., 2000; Diallo et al., 2010; Listorti et al., 2013; Franzo et al., 2015; Wang et al., 2015; De la Torre et al., 2018; Mescolini et al., 2019).

Birds were tagged and divided into three groups housed in separate isolators (from 10 to 25 birds per isolator) as follows: ITA-IBDV (35 birds), G1a-IBDV (35 birds) and a Control group ( 25 birds). At 35 days of age, the ITA-IBDV and G1a-IBDV groups were orally inoculated with a dose of $10^{4.5}$ EID $_{50} /$ bird of the ITA or G1a viruses, respectively. Chickens in the control group were kept as negative controls and mock-inoculated with sterile water. After inoculation, the birds were monitored and scored daily for clinical signs, as previously described (Le Nouen et al., 2012).

Before inoculation, and at 7, 14, 21 and 28 days post-inoculation (dpi), ten birds per group were bled and their sera were tested for anti-IBDV antibodies using the commercial ELISA Infectious Bursal Disease Virus Antibody test kit (BioCheck, Reeuwijk, The Netherlands), according to the manufacturer's instructions. At 2, 4, 7, 14, 21 and 28 dpi, five birds from the ITA-IBDV group, five from the G1a-IBDV group and three from the control group were euthanised, weighed and examined for macroscopic lesions post-mortem. Bursa and thymus tissues were collected and weighed for the subsequent calculation of the bursa:body weight (B:BW) or thymus:body weight (T:BW) ratios, following the formula described by Sharma et al. (1989). Bursa and thymus tissues were fixed in 10\% neutral buffered formalin for processing (Dalle Zotte et al., 2017) ready for the histological scoring of lesions. Bursa lesions were scored from 0 to 4 , on the basis of lymphoid necrosis and/or depletion, according to Sharma et al. (1989). Thymus lesions were evaluated on the basis of cortex atrophy and expressed as a percentage of cortex area/lobule area. Photomicrographs of two thymic lobules from each thymus sample were acquired with a digital camera connected to an optical microscope; digital image analysis was performed using ImageJ software (Schneider, Rasband, \& Eliceiri, 2012). Thymic medulla and lobule images were manually aligned in order to calculate their areas.

Statistical analyses were performed using R (version 3.5.2). Values are expressed as mean \pm standard deviation (SD), with the exception of bursa score, which is expressed as median - interquartile range, and the level of significance was set at $p \leq 0.05$. A mixed effect model was used to determine inoculations and time effects and their interaction, with the repetition as a random effect. For bursa scores a general linear model was used.

\section{RESULTS}


During the study, neither clinical signs nor mortality were observed in any of the experimental groups. During post-mortem examination, the bursae of Fabricius of birds from both virus-inoculated groups were enlarged from $2 \mathrm{dpi}$, and a gelatinous yellowish transudate covered the serosal surface. Atrophy of the bursae was observed at 4 dpi in the ITA-IBDV group and at 7 dpi in birds in the G1a-IBDV group. This atrophy lasted until the end of the experiment. No noticeable macroscopic lesions were observed in the thymus. From 2 to 7 $\mathrm{dpi}$, areas of haemorrhage in the thigh muscles and/or a slight enlargement of the spleen, showing grey foci uniformly dispersed on the surface, were observed in both inoculated groups. No post-mortem lesions were observed in the control birds at any time. The mean bursa:body weight (B:BW) and thymus:body weight (T:BW) ratios are presented in Figure 1. At 4 dpi, the mean B:BW ratio of the ITA-IBDV group was significantly lower than the mean B:BW ratios of the G1a-IBDV and control groups ( $p<0.05)$, confirming the results of the post-mortem examination. Although not significantly different, at 4 dpi the mean T:BW ratio of the G1a-IBDV group was lower than that of the ITA-IBDV group and of the control group ( $>0.05)$.

No ELISA anti-IBDV antibodies were detected in the control group at any time during the trial or in the ITAIBDV and G1a-IBDV groups before inoculation. Anti-IBDV antibodies were however detected from 7 dpi, and titres increased up to the end of the trial in both inoculated groups. At 7 dpi, birds in the ITA-IBDV group had a significantly higher mean antibody titre than birds in the G1a-IBDV group, although any differences were not significant on any of the subsequent sampling days (Figure 2).

The bursa and thymus mean microscopic lesion scores are reported in Table 1. Extensive microscopic lesions were observed in the bursa of virus-exposed birds from $2 \mathrm{dpi}$, and persisted throughout the 28-day observation period (Figure 3). A statistically significant difference between the mean bursa scores of the virus-inoculated groups was recorded at $2 \mathrm{dpi}(\mathrm{p}<0.05)$, with higher scores in the ITA-IBDV group. On the subsequent sampling days, the mean bursa scores of both virus-inoculated groups were significantly higher than the mean of the control group $(\mathrm{p}<0.05)$, but did not differ from each other $(\mathrm{p}>0.05)$.

Thymus cortical atrophy was observed upon histopathological examination in the virus-inoculated birds at 2 and 4 dpi (Figure 3). At 2 dpi, the mean thymus lesion score was lower, but not significantly (p>0.05), in the ITA-IBDV group than in the G1a group; at 4 dpi the mean thymus lesion score of the G1a-inoculated group was similar to that in the ITA group but differed from the control, with lower score in the G1a group ( $<<0.05)$. 


\section{DISCUSSION}

In the present study, a pathogenicity trial was conducted by the inoculation of 5-week-old SPF chickens with an IBDV strain recognised to belong to the ITA genotype, in order to assess its pathogenicity in comparison to a strain belonging to the G1a genogroup. In order to avoid an alteration of the results due to the possible attenuation of the strains after passage through the culture system used for virus isolation (Rodriguez-Chavez et al., 2002), both viruses tested for pathogenicity underwent only one passage in embryonated SPF chicken eggs. Furthermore, full sequencing of the virus genomes, extracted directly from the original samples or from inoculated CAMs, was performed to exclude the occurrence of nucleotide mutations, and showed that viruses had $100 \%$ nucleotide identity between them before and after inoculation in SPF eggs (data not shown).

Either the IBDV-ITA strain and the G1a strain tested in the present study induced a subclinical course of disease, with no clinical signs or mortality recorded during the study, even in the presence of typical IBDV post-mortem lesions. Bursal damage, measured by the bursa:body weight ratio, was more noticeable and precocious after ITA-IBDV inoculation. This feature has previously been described for "variant" IBDV, which has been reported to cause earlier and more severe bursal atrophy than "classical" strains (Hassan, Al-Natour, Ward \& Saif, 1996; Jayasundara et al., 2017; Sharma et al., 1989). The histopathology scores of the bursa confirmed the aggressiveness of the ITA-IBDV strain tested in this organ, with scores indicating severe lymphoid depletion, as previously reported by Sharma et al. (1989) for the American "variant" strain.

It should be noted that the clinical and pathological course of the infection observed in chickens after inoculation of the tested viruses (either the ITA or the G1a strains) cannot be transposed to all strains of the same genotype, since it has been shown that in the same genotype strains can have different pathogenic potential (Jackwood et al., 2018).

It is widely recognised that the IBDV-induced damage to the bursa of Fabricius is related to immunosuppression; moreover, IBDV strains that have been shown to involve other lymphoid organs, such as the thymus, can cause even more severe immune disorders (Sharma et al., 1989; Sharma, Dohms, Walser, \& Snyder, 1993). Thymus lymphoid tissue damage is reported to be indicative of the highly aggressive nature of the examined IBDV strain (Sharma, Dohms, Walser \& Snyder, 1993; Tanimura, Tsukamoto, Nakamura, Narita, \& Maeda, 1995; Tsukamoto, Tanimura, Mase, \& Imai, 1996), and may represent a generalised 
inflammatory response to an acute virus infection (Sharma et al., 1989). In the present study, a reduction in the size of the thymus cortex was observed at the microscopic level in IBDV-inoculated birds in the early days post infection; this was not associated with atrophy of the organ, as described previously (Sharma et al., 1989).

A significantly earlier antibody response was detected in the ITA-IBDV group compared to the G1a-IBDV group. This characteristic was previously considered to be an indicator of high pathogenicity, in the acute phase of IBDV infection, for an Australian variant strain (Jayasundara et al., 2017). During IBDV infection, it is known that the immune response against the virus itself is not affected; this seems to be a paradox as there is immunosuppression with respect to other antigens. Different mechanisms could be involved that selectively stimulate the proliferation of the B cells committed to anti-IBDV antibody production (Jakka, Reddy, Kirubaharan, \& Chandran, 2014; Withers, Young, \& Davison, 2005).

The protection offered by common vaccination schedules to ITA-IBDV remains unknown and needs to be further investigated by in vivo cross-protection studies using existing IBDV vaccines. Strains of the ITA genotype are still circulating in Italy (Lupini et al., 2018) and are often underdetected during routine clinical diagnostic activity. Due to the absence of overt clinical signs and mortality, they can remain uncontrolled and cause production losses given their deleterious immunosuppressive potential.

\section{ETHICS STATEMENT}

This experimental trial was performed in agreement with European regulations on animal experiments and animal welfare (EC, 2010), according to authorisation $\mathrm{N}^{\circ} 635 / 2015-\mathrm{PR}$, provided by the Italian Ministry of Health.

\section{References}

Abdel-Alim, G. A., \& Saif, Y. M. (2001). Immunogenicity and antigenicity of very virulent strains of Infectious Bursal Disease Viruses. Avian Diseases, 45, 92-101.

Abdul, R., Murgia, M. V., Rodriguez-Palacios, A., Lee, C.-W., \& Saif, Y. M. (2013). Persistence and tissue distribution of Infectious Bursal Disease Virus in experimentally infected SPF and commercial broiler chickens. Avian Diseases, 57, 759-766. doi: 10.1637/10448-110812-Reg.1 
Boot, H. J., ter Huurne, A. A., Hoekman, A.J, Peeters, B. P., \& Gielkens, A.L. (2000). Rescue of very virulent and mosaic infectious bursal disease virus from cloned cDNA: VP2 is not the sole determinant of the very virulent phenotype. Journal of Virology, 74:6701-11. doi:10.1128/jvi.74.15.6701-6711.2000

Cosgrove, A. S. (1962). An Apparently New Disease of Chickens: Avian Nephrosis. Avian Diseases, 6, $385-389$.

Dalle Zotte, A., Tasoniero, G., Puolanne, E., Remignon, H., Cecchinato, M., Catelli, E. \& Cullere M. (2017): Effect of "Wooden Breast" appearance on poultry meat quality, histological traits, and lesions characterization. Czech Journal of Animal Science, 62, 51-57. doi: 10.17221/54/2016-CJAS

De la Torre, D., I., Nuñez, L., F. Astolfi-Ferreira, C. S., \& Ferreira A., J., P. (2018) Enteric Virus Diversity Examined by Molecular Methods in Brazilian Poultry Flocks. Veterinary Science 5: 38. doi:10.3390/vetsci5020038

Delmas, B., Attoui H., Ghosh S., Malik Y. S., Mundt E., Vakharia V. N., \& ICTV Report Consortium. (2019). ICTV virus taxonomy profile: Birnaviridae. Journal of General Virology, 100, 5-6. doi:10.1099/jgv.0.001185

Diallo, I.,S., Taylor, J., Gibson, J., Hoad, J., De Jong, A., Hewitson, G., Corney, B.,G., \& Rodwell, B.,J. (2010) Diagnosis of a naturally occurring dual infection of layer chickens with fowlpox virus and gallid herpesvirus 1 (infectious laryngotracheitis virus) Avian Pathology; 39:25-30. doi: 10.1080/03079450903447412.

Escaffre, O., Le Nouën, C., Amelot, M., Ambroggio, X., Ogden, K.M., Guionie, O., Toquin, D., Müller, H., Islam, M.R. \& Eterradossi N. (2013) Both genome segments contribute to the pathogenicity of very virulent infectious bursal disease virus. Journal of Virology ;87:2767-80. doi: 10.1128/JVI.02360-12.

European Commission (2010). Directive 2010/63/EU of the European Parliament and of the council of 22 September 2010 on the protection of animals used for scientific purposes. Available at: http://eurlex.europa.eu/LexUriServ/LexUriServ.do?uri=OJ:L:2010:276:0033:0079:EN:PDF

Felice, V., Franzo, G., Catelli, E., Di Francesco, A., Bonci, M., Cecchinato, M., Mescolini, G., Giovanardi, D., Pesente, P., \& Lupini, C. (2017). Genome sequence analysis of a distinctive Italian infectious bursal disease virus. Poultry Science, 96, 4370-4377. doi: 10.3382/ps/pex278

Fouchier, R.A.M., Bestebroer, T.M., Herfst, S., Van Der Kemp, L, Rimmelzwaan \& Osterhaus, A.D.M.E. (2000). Detection of Influenza A Virus from Different Species by PCR Amplifcation of Conserved sequences in the Matrix Gene. Journal of Clinical Microbiology 38, 4096-4101. 
Franzo, G., Listorti, V., Naylor, C.J., Lupini, C., Laconi, A., Felice, V., Drigo, M., Catelli, E., \& Cecchinato, M. (2015) Molecular investigation of a full-length genome of a Q1-like IBV strain isolated in Italy in 2013.

Virus Research, 210:77-80. doi: 10.1016/j.virusres.2015.07.008.

Hassan, M. K., Al-Natour, M. Q., Ward, L. A. \& Saif Y. M. (1996). Pathogenicity, Attenuation, and Immunogenicity of Infectious Bursal Disease Virus. Avian Diseases, 40, 567-571. doi: 10.2307/1592265

Hirai, K., \& Calnek, B.W. (1979). In vitro replication of infectious bursal disease virus in established lymphoid cell lines and chicken B lymphocytes. Infection and Immunity, 25, 964-970.

Imai, K., Mase, M., Yamaguchi, S., Yuasa, N., \& Nakamura, K. (1998). Detection of chicken anaemia virus DNA from formalin-fixed tissues by polymerase chain reaction. Research in Veterinary Science, 64, 205-208.

Ingrao, F., Rauw, F., Lambrecht, B., \& van den Berg, T. (2013). Infectious Bursal Disease: A complex hostpathogen interaction. Chicken Immunology, 41, 429-438. doi: 10.1016/j.dci.2013.03.017

Jackwood, D. J., Schat, K. A., Michel, L. O., \& de Wit S. (2018) A proposed nomenclature for infectious bursal disease virus isolates. Avian Pathology, 47(6), 576-584. doi: 10.1080/03079457.2018.1506092.

Jackwood D. J., Sreedevi B., LeFever L. J., \& Sommer-Wagner S. E. (2008) Studies on naturally occurring infectious bursal disease viruses suggest that a single amino acid substitution at position 253 in VP2 increases pathogenicity. Virology, 377 110-116. doi: 10.1016/j.virol.2008.04.018.

Jakka, P., Reddy, Y. K., Kirubaharan, J. J., \& Chandran, N. D. (2014) Evaluation of immune responses by live infectious bursal disease vaccines to avoid vaccination failures. European Journal of Microbiology and Immunology, 4, $123-127$. doi: 10.1556/EuJMI.4.2014.2.5.

Jayasundara, J. M. K. G. K., Walkden-Brown, S. W., Katz, M. E., Islam, A. F. M. F., Renz, K. G., McNally, J., \& Hunt, P. W. (2017). Pathogenicity, tissue distribution, shedding and environmental detection of two strains of IBDV following infection of chickens at 0 and 14 days of age. Avian Pathology, 46, 242-255. doi: 10.1080/03079457.2016.1248898

Le Nouën, C., Toquin, D., Müller, H., Raue, R., Kean, K. M., Langlois, P., Cherbonnel, M., \& Eterradossi, N. (2012). Different domains of the RNA polymerase of infectious bursal disease virus contribute to virulence. PLoS ONE 7, e28064. doi: 10.1371/journal.pone.0028064. 
Listorti, V., Lupini, C., Cecchinato, M., Pesente, P., Rossi, G., Giovanardi, D., Naylor, C.J., \& Catelli, E. (2013) Rapid detection of subtype B avian metapneumoviruses using RT-PCR restriction endonuclease digestion indicates field circulation of vaccine-derived viruses in older turkeys. Avian Pathology, 43:51-6. doi: 10.1080/03079457.2013.866212.

Lupini, C., Giovanardi, D., Pesente, P., Bonci, M., Felice, V., Rossi, G., Morandini, E., Cecchinato, M., \& Catelli, E. (2016). A molecular epidemiology study based on VP2 gene sequences reveals that a new genotype of infectious bursal disease virus is dominantly prevalent in Italy. Avian Pathology, 45, 458-464. doi: 10.1080/03079457.2016.1165792

Lupini, C., Mescolini, G., Quaglia G., Silveira, F., Felice, V., \& Catelli, E. (2018) Indagine di campo sulla circolazione di virus immunosoppressivi nel pollo da carne. In: Atti della Società Italiana di Patologia Aviare 2018 III Simposio Scientifico (pp.135), Parma, 14 Settembre 2018.

Mescolini, G., Lupini, C., Felice, V., Guerrini, A., Silveira, F., Cecchinato, M., \& Catelli, E. (2019) Molecular characterization of the meq gene of Marek's disease viruses detected in unvaccinated backyard chickens reveals the circulation of low- and high-virulence strains. Poultry Science. doi: 10.3382/ps/pez095.

Michel, L. O., \& Jackwood, D. J. (2017). Classification of infectious bursal disease virus into genogroups. Archives of Virology, 162, 3661-3670. doi: 10.1007/s00705-017-3500-4.

Nagarajan, M. M., \& Kibenge, F. S. (1997). Infectious bursal disease virus: a review of molecular basis for variations in antigenicity and virulence. Canadian Journal of Veterinary Research, 61, 81-88.

Raue, R., \& Hess, M. (1998). Hexon based PCRs combined with restriction enzyme analysis for rapid detection and differentiation of fowl adenoviruses and egg drop syndrome virus. Journal of Virological Methods, 73, 211-217. doi: S0166-0934(98)00065-2

Reed, D., \& Muench, H. (1938). A simple method of estimating fifty percent endpoints. American Journal of Epidemiology, 27, 493-497.

Rodriguez-Chavez, I.R., Rosenberger, J.K., Cloud, S.S., \& Conrad R.P. (2002). Characterization of the antigenic, immunogenic, and pathogenic variation ofinfectious bursal disease virus due to propagation in different host systems (bursa, embryo, and cellculture). III. Pathogenicity, Avian Pathology, 31:5, 485-492, DOI: $10.1080 / 0307945021000005851$

Saif, Y. M. (1984). Infectious bursal disease virus type. In: 19th National Meeting on Poultry Health and Condemnations (pp. 105-107). Ocean City, MD, USA . 
Schneider, C. A., Rasband, W. S., \& Eliceiri, K. W. (2012). NIH Image to ImageJ: 25 years of image analysis. Nature Methods, 9, 671-675.

Sharma, J. M., Dohms, J. E., \& Metz, A. L. (1989). Comparative pathogenesis of serotype 1 and variant serotype 1 isolates of infectious bursal disease virus and their effect on humoral and cellular immune competence of specific-pathogen-free chickens. Avian Diseases, 33, 112-124.

Sharma, J. M., Dohms, J. E., Walser, M., \& Snyder, D. B. (1993). Presence of lesions without virus replication in the thymus of chickens exposed to infectious bursal disease virus. Avian Diseases, 37, 741-748.

Silveira, F., Felice, V., Franzo, G., Mescolini, G., Catelli, E., Cecchinato, M., Berto, G., Listorti, V., \& Lupini, C. (2019). Inoculation of specific pathogen-free chickens with an infectious bursaldisease virus of the ITA genotype (G6) leads to a high and persistent viralload in lymphoid tissues and to a delayed antiviral response. Veterinary Microbiology, 235: 136142. doi: 10.1016/j.vetmic.2019.06.014

Sreedevi, B., LeFever, L. J., Sommer-Wagner, S. E., \& Jackwood, D. J. (2007). Characterization of Infectious Bursal Disease Viruses from Four Layer Flocks in the United States. Avian Diseases, 51, 845-850. doi: 10.1637/7923-020607REGR1.1

Tanimura, N., Tsukamoto, K., Nakamura, K., Narita, M., \& Maeda, M. (1995) . Association between pathogenicity of infectious bursal disease virus and viral antigen distribution detected by immunohistochemistry. Avian Diseases, 39:920.

Tsukamoto, K., Tanimura, N., Mase, M. \& Imai K. (1996). Comparison of virus replication efficiency in lymphoid tissues among three infectious bursal disease virus strains. Avian Diseases, 39:844-52.

Wang, J. Y., Liu, W. H., Ren, J. J., Tang, P., Wu, N., Wu, H. Y., Ching, C. D. \& Liu, J. (2015) Characterization of emerging Newcastle disease virus isolates in China. Virology Journal, 12:119. doi: 10.1186/s12985-015-0351-z

Withers, D. R., Young, J. R., \& Davison, T. F. (2005). Infectious bursal disease virus-induced immunosuppression in the chick is associated with the presence of undifferentiated follicles in the recovering bursa. Viral Immunology, 18, $127-37$. doi: 10.1089/vim.2005.18.127 
Table 1. Histological lesion scores of the experimental groups by day post-inoculation (dpi). Bursae score is expressed as median (interquartile range) and thymus atrophy is expressed as mean of the percentage of cortex area/lobule area ( \pm standard deviation) Different superscripts indicate that the difference between groups is statistically significant $(\mathrm{p}<0.05)$.

\begin{tabular}{|c|c|c|c|c|c|c|}
\hline \multirow[b]{2}{*}{ dpi } & \multicolumn{3}{|c|}{ Bursa lesion score } & \multicolumn{3}{|c|}{ Thymus lesion } \\
\hline & G1a-IBDV & ITA-IBDV & Control & G1a-IBDV & ITA-IBDV & Control \\
\hline 2 & $2(2)^{a}$ & $4(0)^{\mathrm{b}}$ & $0(0)^{\mathrm{c}}$ & $65.2( \pm 11.8)^{\mathrm{a}}$ & $58.9( \pm 3.4)^{\mathrm{a}}$ & $71.2( \pm 8.5)^{\mathrm{a}}$ \\
\hline 4 & $4(0)^{\mathrm{a}}$ & $4(0)^{\mathrm{a}}$ & $0(0)^{b}$ & $46.4( \pm 9.0)^{\mathrm{a}}$ & $49.5( \pm 7.0)^{\mathrm{ab}}$ & $65.1( \pm 2.8)^{b}$ \\
\hline 7 & $4(0)^{\mathrm{a}}$ & $4(0)^{\mathrm{a}}$ & $0(0)^{\mathrm{b}}$ & $65.7( \pm 3.1)^{\mathrm{a}}$ & $62.2( \pm 5.8)^{\mathrm{a}}$ & $72.9( \pm 4.2)^{\mathrm{a}}$ \\
\hline 14 & $4(0)^{\mathrm{a}}$ & $4(0)^{\mathrm{a}}$ & $0(0)^{\mathrm{b}}$ & $64.6( \pm 6.2)^{\mathrm{a}}$ & $67.9( \pm 4.2)^{\mathrm{a}}$ & $65.7( \pm 8.9)^{\mathrm{a}}$ \\
\hline 21 & $4(0)^{\mathrm{a}}$ & $4(0)^{a}$ & $0(0)^{\mathrm{b}}$ & $65.1( \pm 6.0)^{\mathrm{a}}$ & $67.2( \pm 4.9)^{\mathrm{a}}$ & $66.9( \pm 5.6)^{\mathrm{a}}$ \\
\hline 28 & $4(0)^{\mathrm{a}}$ & $4(0)^{\mathrm{a}}$ & $0(0)^{\mathrm{b}}$ & $59.9( \pm 5.2)^{\mathrm{a}}$ & $56.7( \pm 7.8)^{\mathrm{a}}$ & $57.8( \pm 7.0)^{\mathrm{a}}$ \\
\hline
\end{tabular}


Figure 1. Mean bursa (A) or thymus (B):body weight (BW) ratios ( \pm standard deviations) of experimental groups by day post-inoculation (dpi) with G1a-IBDV and ITA-IBDV. Different superscripts indicate that the difference between groups is statistically significant $(\mathrm{p}<0.05)$.
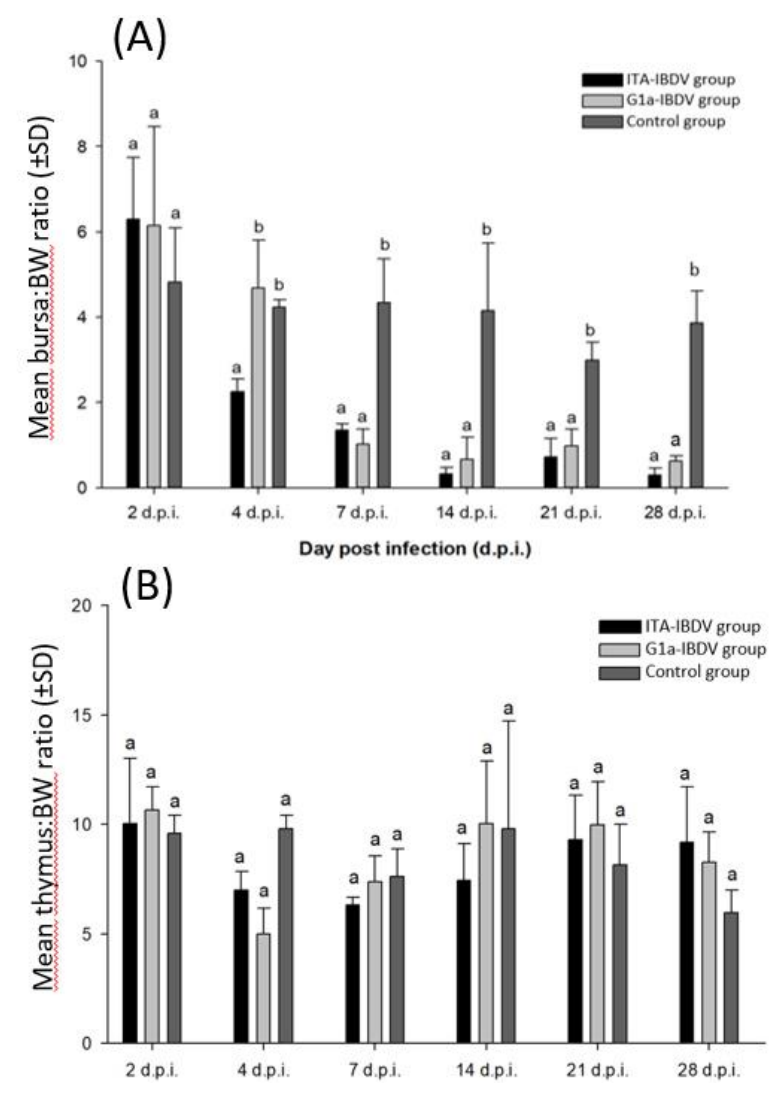

Figure 2. Mean IBDV antibody titres in the ITA-IBDV and G1a-IBDV groups, according to days postinoculation. Different letters indicate that the difference between groups is statistically significant $(\mathrm{p}<0.05)$.

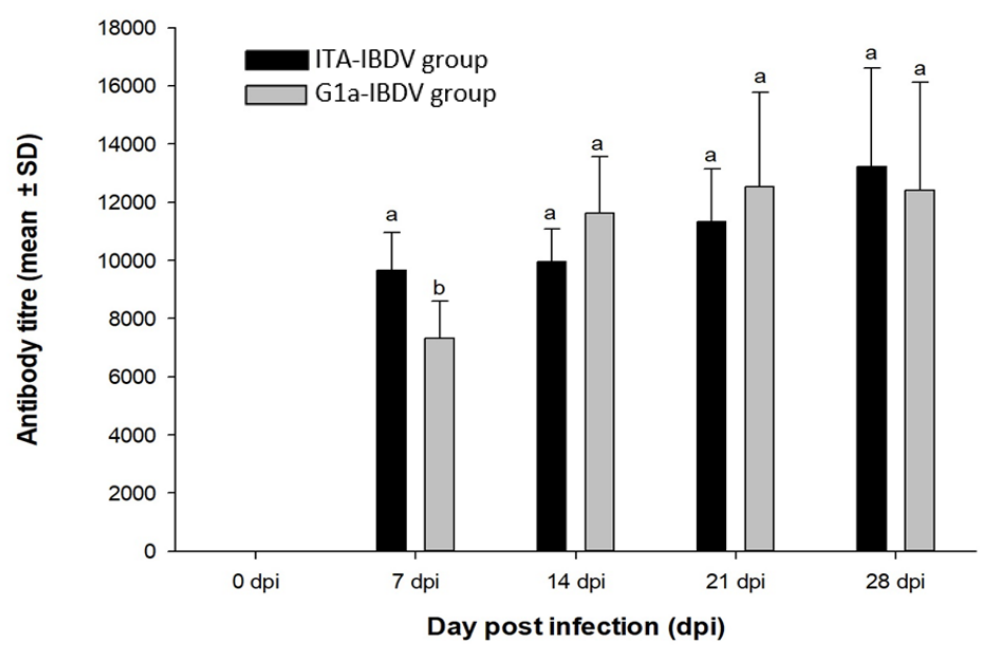


Figure 3. Histopathology of the bursa of Fabricius and thymus of specific-pathogen-free chickens (X40 magnification, A-C, H-O; X100 magnification E-G). Control birds: normal lymphoid follicles of the bursa at 2 (A), 4 (D) and $14(\mathrm{H})$ days post inoculation (dpi)-scores 0. ITA-IBDV birds: severe follicular lymphocyte depletion of bursa at 2 (B-score 4) and 4 dpi (E-score 4); fold atrophy and follicular lymphocyte depletion at 14 dpi (I-score 4); G1a-IBDV birds: mild to severe follicular lymphocyte depletion of bursa at 2 (C-score 3) and 4 (F-score 4) dpi,;fold atrophy and follicular lymphocyte depletion at 14 dpi (F-score 4). Thymus at 4 days post-inoculation: (M) virus-free control; cortical atrophy in ITA-IBDV (N) and G1a (O) birds.

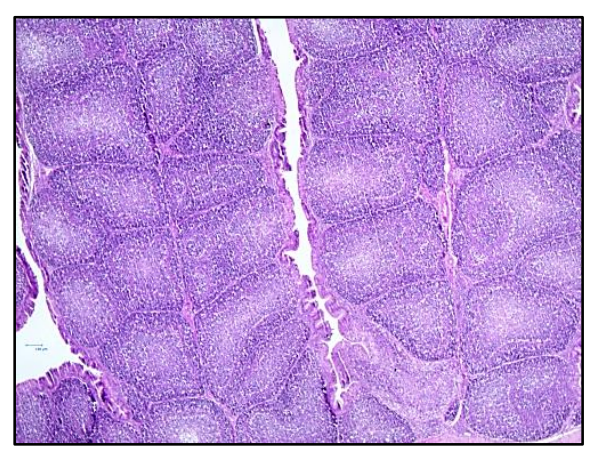

(A)

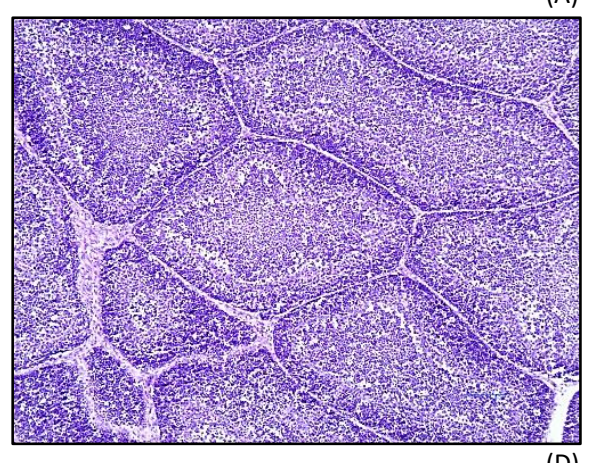

(D)

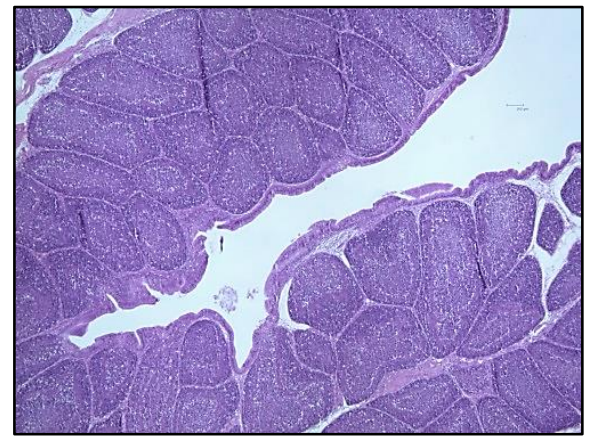

(H)

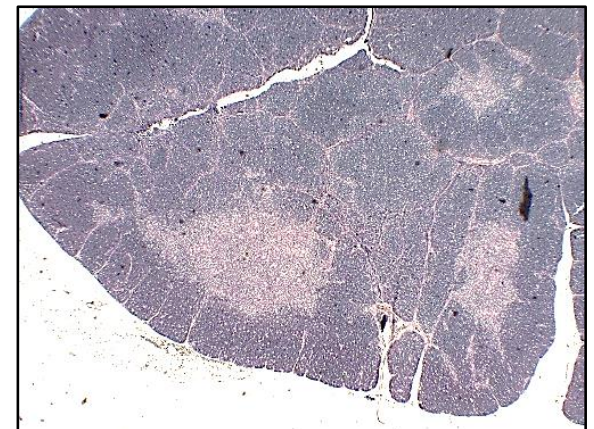

(M)

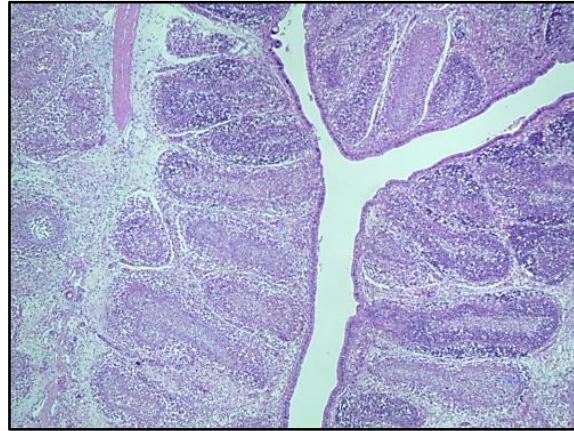

(B)

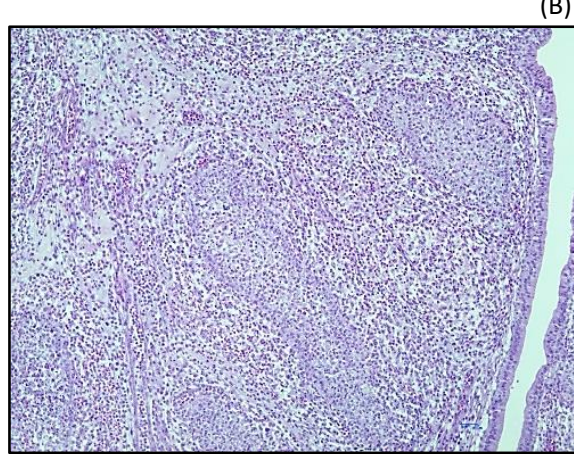

(E)

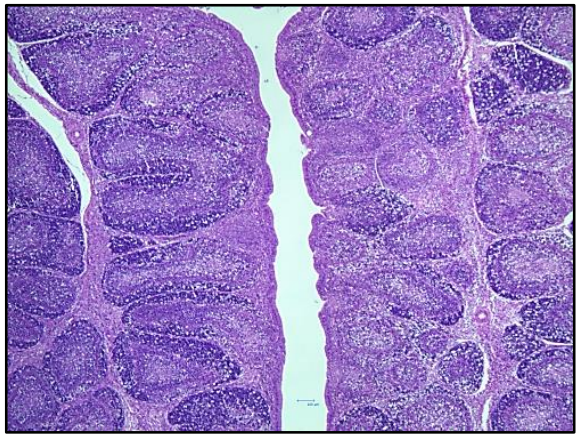

(C)

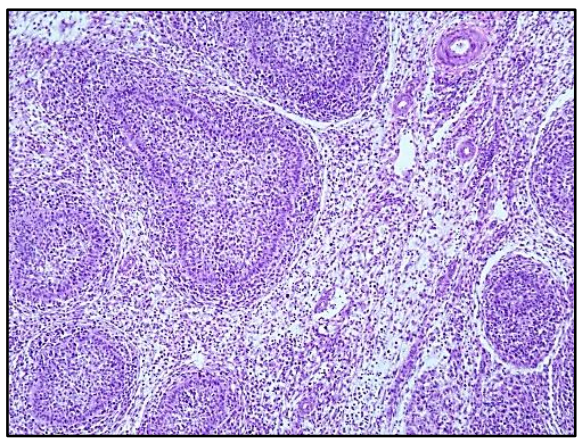

(F)

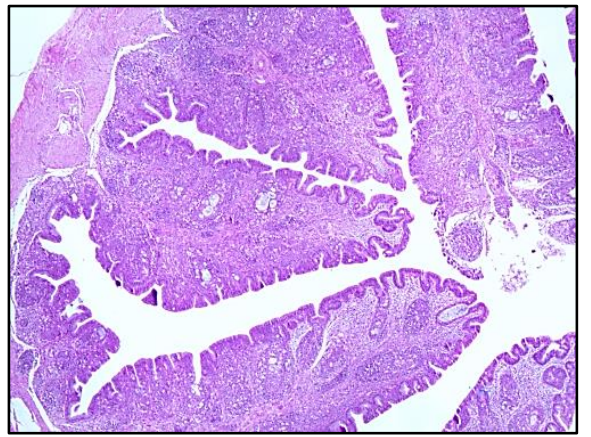

(I)

(L)
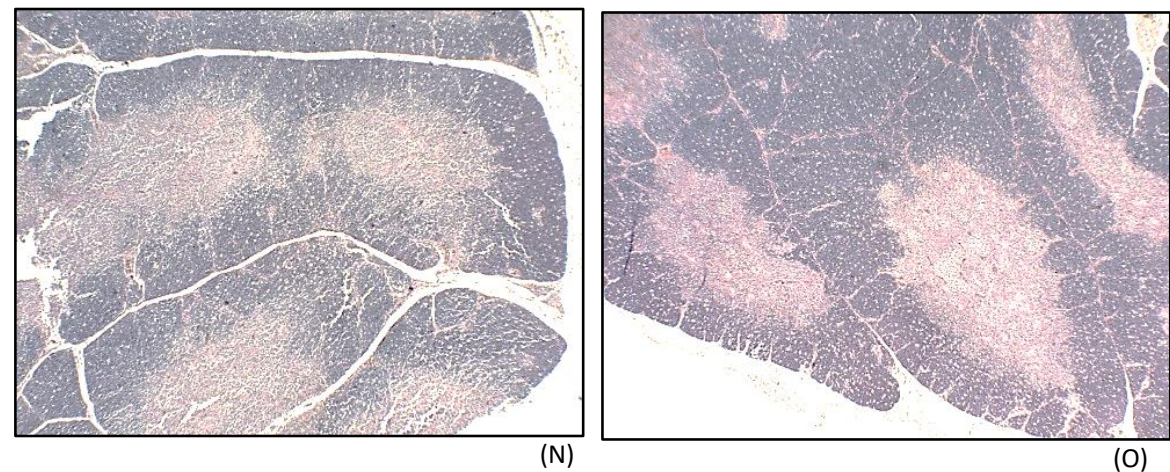

(O) 